\title{
Photoacid Generators Activated Through Sequential Two-Photon Excitation: 1-Sulfonatoxy-2- alkoxyanthraquinone Derivatives
}

Andrea N. Zeppuhar, Steven M. Wolf, and Daniel E. Falvey*

Department of Chemistry and Biochemistry, University of Maryland, College Park, MD 20742 (USA)

*Email: falvey@umd.edu

\begin{abstract}
Two sulfonate ester derivatives of anthraquinone, 1-tosyloxy-2-methoxy-9,10-anthraquinone (1a) and 1-trifluoromethylsulfonoxy-2-methoxy-9,10-anthraquinone (1b) were prepared and their ability to produce strong acids upon photoexcitation was examined. It is shown that these compounds generate acid with a yield that increases with light intensity when the applied photon dose is held constant. Additional experiments show that the rate of acid generation increases 4 fold when visible light $(532 \mathrm{~nm})$ laser pulses are combined with ultraviolet $(355 \mathrm{~nm})$ compared with ultraviolet alone. Continuous wave diode laser photolysis also effects acid generation with a rate that depends quadratically on the light intensity. Density functional theory calculations, laser flash photolysis, and chemical trapping experiments support a mechanism whereby an initially formed triplet state $\left(T_{1}\right)$ is excited to a higher triplet state which in turn undergoes homolysis of the $\operatorname{RS}\left(\mathrm{O}_{2}\right)-\mathrm{OAr}$ bond. Secondary reactions of the initially formed sulfonyl radicals produce strong acids. It is demonstrated that high intensity photolysis of either $\mathbf{1 a}$ or $\mathbf{1} \mathbf{b}$ can initiate cationic polymerization of ethyl vinyl ether.
\end{abstract}

\section{Introduction}

Photochemical generation of reactive intermediates such as radicals, ${ }^{1-9}$ nitrenes, ${ }^{10-14}$ cations, ${ }^{15-18}$ bases, $^{19,20}$ and protons ${ }^{21-23}$ is a method for initiating useful chemical reactions that require high spatiotemporal specificity. The specificity from photochemical processes enables applications in numerous areas including photopharmocology, photoimaging, and photolithography. A recent development has been to generate reactive intermediates using non-resonant two-photon absorption (nr-TPA). ${ }^{24-31}$ In this procedure, two photons, which individually lack the energy to populate the targeted excited state, are absorbed simultaneously by the substrate molecule. This procedure allows for the use of high wavelength visible photons to promote photochemical reactions that would otherwise require low wavelength ultraviolet photons. Another attractive feature of nr-TPA is that the quadratic dependence of the excitation rate on light intensity allows for higher spatial resolution. Many exciting 
applications of nr-TPA have been described. ${ }^{31-36}$ However, one drawback to this method is that the high photon densities required for simultaneous absorption typically require the use of expensive femtosecond lasers and/or high resolution optical set-ups. This in turn increases the expense and limits the ability to run such processes on scale. In an effort to overcome this drawback, several research groups have begun to explore stepwise two-photon excitation (s-TPA), described in Scheme $1 .{ }^{37-53}$

Scheme 1. Idealized scheme of a stepwise, two-photon absorption process

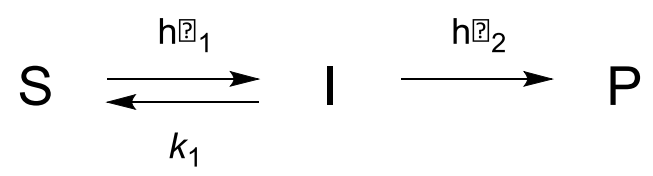

Initial excitation of a substrate (S) generates an intermediate species (I). The latter either relaxes back to $S$ or, if it absorbs a second photon, dissociates to form the species of interest $(P)$. The intermediate species in such a scheme could be an excited triplet state, a photoisomer in a thermally reversible photochromic system, or a reactive intermediate that thermally reverts to $\mathrm{S}$. As discussed in a recent review by $A b e,{ }^{52}$ if I lives for microseconds to seconds, then it is possible to realize effective two-photon excitation using inexpensive $\mathrm{mW}$ CW lasers or, in favorable cases, incoherent light sources. However, a significant challenge to the further development of S-TPA is identifying intermediate species that produce useful products upon excitation. The ephemeral nature of such species (triplets, high energy photoisomers) means that there is little empirical data on their photochemical behavior available to guide their design.

Photoacid generators (PAGs) are compounds that, upon irradiation, undergo reactions or dissociations to generate acids as one of the photoproducts. ${ }^{22}$ Applications of PAGs are in areas including biological probing, ${ }^{54}$ photodynamic therapy, ${ }^{55,56}$ and polymerization initiation. An early example of a sequential two-photon photoacid generation system was reported by Turro and coworkers. ${ }^{57}$ In that system, a UV photon activates a latent photosensitizer molecule and the second photon initiates an excited state electron transfer reaction leading to acid production. A drawback to that system is that the sensitizer and acid generating species are separate molecules. This report proposes photoacid generators in which the chromophore and the acid generating species are combined in a single molecule.

The following report describes a photoacid generator (PAG) that is activated via s-TPA. Specifically, it is shown that S-TPA of 1-tosyloxy-2-methoxy-9,10-anthraquinone 1a and 1- 
(trifluoromethylsulfonoxy)-2-methoxy-9-10-anthraquinone 1b (Figure 1) generate strong acids in excellent chemical yields. Several observations including laser flash photolysis, effect of laser power on the rate of acid formation, and comparison with derivatives that show no s-TPA activity indicate that the likely intermediate state that is re-excited in this system is the first excited triplet state of the precursor $\left(\mathrm{T}_{1}\right)$. Re-excitation of the latter promotes a homolytic $\mathrm{S}-\mathrm{O}$ bond scission that is not energetically available to $T_{1}$. Acids result from subsequent radical reactions.

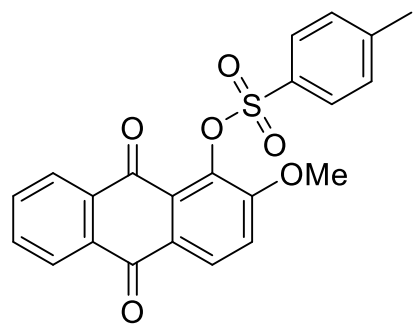

$1 \mathrm{a}$<smiles>COc1ccc2c(c1OS(=O)(=O)C(F)(F)F)C(=O)c1ccccc1C2=O</smiles>

$1 b$

Figure 1. Photoacid generators studied in this work

\section{Results and Discussion}

Design and DFT Calculations. For medium to large molecules in solution, it is widely assumed that photochemical reactions proceed via thermally equilibrated species in their lowest excited states $\left(S_{1}\right.$ or $\left.T_{1}\right)$. This generalization follows because a high density of vibronic states above $S_{1}$ and $T_{1}$, along with rapid collisions with solvent molecules makes radiationless relaxation faster than the making or breaking of covalent bonds. There are, however, exceptions to this generalization. ${ }^{58}$ For example, certain thiocarbonyl compounds show reactivity and fluorescence from $S_{2}$ states while $S_{1}$ is comparatively inert. $^{59-61}$ Two-color laser experiments have revealed that certain $\alpha$-diketones, ${ }^{37}$ arylhalides, ${ }^{40}$ and arylethers ${ }^{47,62,63}$ dissociate from upper triplet states $\left(T_{n}\right)$ in cases where the corresponding $T_{1}$ state is unreactive or weakly reactive.

Earlier reports ${ }^{64,65}$ demonstrate that various arylsulfonate esters can generate sulfonic acids via a 1-photon photohomolytic pathway. However, in the previous examples, the desired bond breaking was achieved via high-energy excited states, requiring low wavelength UV excitation as outlined in Scheme 2. To see if this process could be adapted to stepwise two-photon excitation, sulfonate esters based on the anthraquinone chromophore were explored. Anthraquinone derivatives are known to absorb near UV to blue light wavelengths (350-450 nm, depending on substitution), and many of these species intersystem cross with high efficiency, forming lower energy $T_{1}$ states (ca. $\left.60 \mathrm{kcal} / \mathrm{mol}\right){ }^{66,67}$ It 
was hypothesized that: (1) anthraquinone $T_{1}$ states would not possess sufficient energy for efficient $S-$ $\mathrm{O}$ bond homolysis and (2) these $T_{1}$ states would have sufficient lifetime and visible absorption that reexcitation would populate a higher energy triplet state leading to rapid dissociation (Scheme 3 ).

Scheme 2. Mechanism of 1-photon photoacid generation from arylsulfonate esters

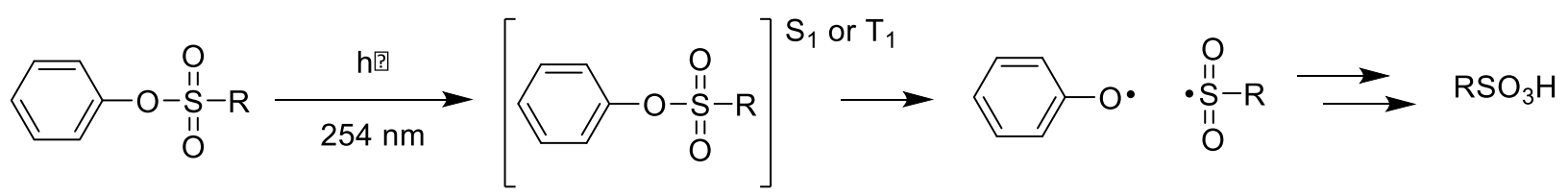

Scheme 3. Proposed mechanism of 2-photon photoacid generation from substituted anthraquinone sulfonate esters
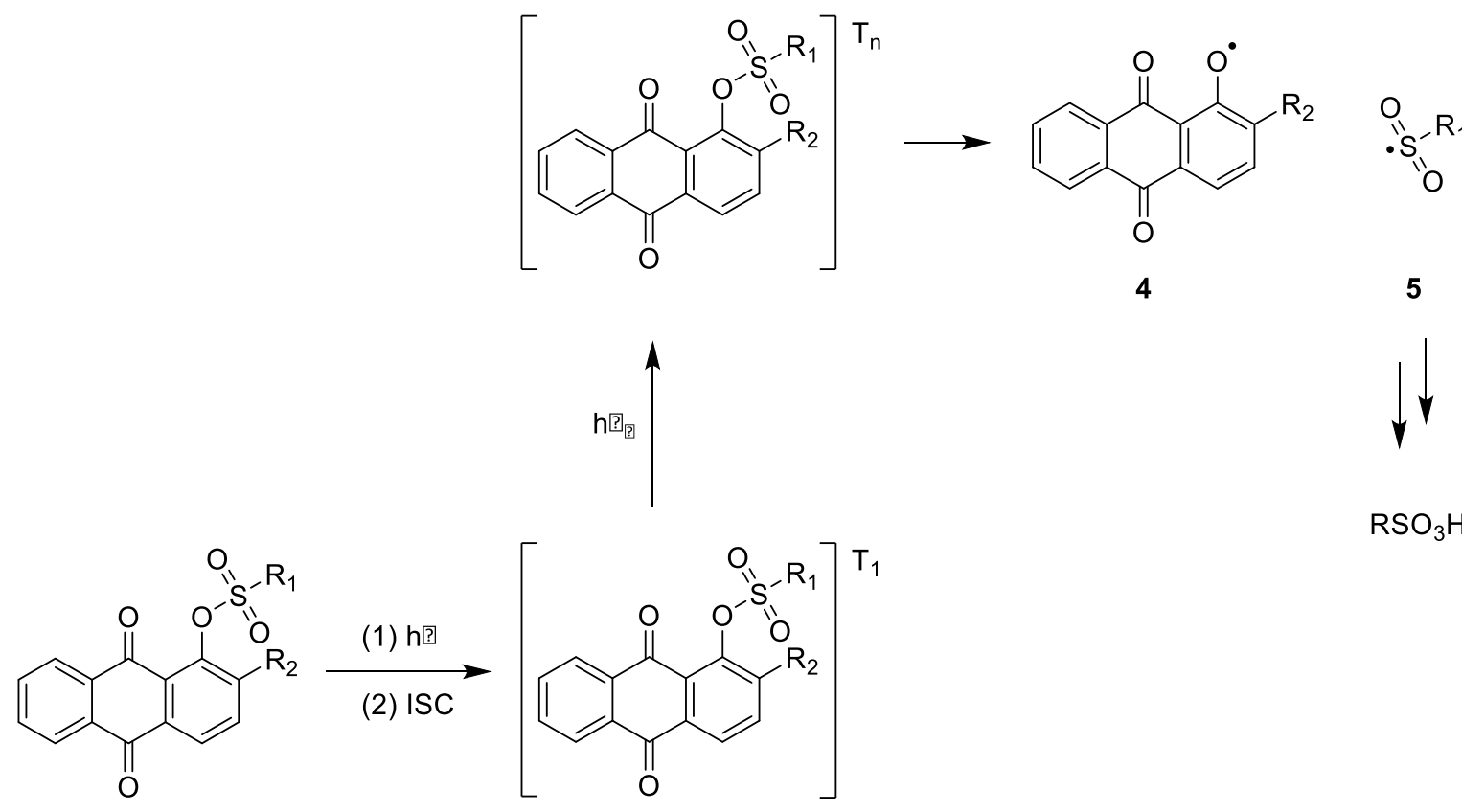

$\mathrm{RSO}_{3} \mathrm{H}$

1

A good substrate for these purposes would possess a bond dissociation energy (BDE) that is higher than, or nearly the same as, the energy available to the lowest excited triplet state, $T_{1}$. In this case the latter state would be able to serve as I in Scheme 1. Obviously, prompt dissociation via $\mathrm{T}_{1}$ would lead to standard 1-photon photochemistry. On the other hand, a S-O bond that is too strong would presumably fail to dissociate, even upon a second excitation. To determine the suitability of the anthraquinone chromophore for s-TPA, DFT calculations were carried out to ascertain bond dissociation energies and barriers for $\mathrm{S}-\mathrm{O}$ homolysis. Specifically, the geometries of the ground state $\left(\mathrm{S}_{0}\right)$ and $\mathrm{T}_{1}$ for compound 1a were optimized at the $(\mathrm{u}) \mathrm{B} 3 \mathrm{LYP} / 6-311 \mathrm{G}(\mathrm{d})$ level and energies were evaluated using 
(u)MN12-SX/6-311(3d). Similar calculations were carried out to evaluate the presumed radical products, the toluenesulfonyl radical (5a) and the anthraquinone based radical (4). The particular combination of functional and basis set was chosen as it was shown to give accurate values for S-O BDEs in smaller model systems for which experimental values are available. The results of these calculations are summarized in Figure 2.

The DFT calculations predict a bond dissociation enthalpy (298 K, $1 \mathrm{~atm}$ ) of $54 \mathrm{kcal} / \mathrm{mol}$. This is reasonably consistent with experimental values for similar systems. For example, $\mathrm{HO}-\mathrm{SO}_{2} \mathrm{CH}_{3}$ shows a $\mathrm{S}-\mathrm{O} \mathrm{BDE}$ of $87 \mathrm{kcal} / \mathrm{mol}^{68}$ Given the increased steric strain in the reactant and additional resonance stabilization available to the products, the $54 \mathrm{kcal} / \mathrm{mol}$ value for $1 \mathrm{a}$ is plausible estimate.

The DFT calculations show that there is a substantial kinetic barrier $\mathrm{S}-\mathrm{O}$ homolysis from $\mathrm{T}_{1}$. The energy of $T_{1}$ for 1 a relative to $S_{0}$ was computed in a similar way as the BDE values. In this case, single point energy calculations were carried using (u)M06-2X/6-311G(2d, 3p) as this combination was shown to give good agreement for singlet-triplet energy gaps in model systems for which experimental data was available. These calculations show that the relaxed triplet state lies $59 \mathrm{kcal} / \mathrm{mol}$ above $\mathrm{S}_{0}$ making S$\mathrm{O}$ bond scission weakly exothermic. To evaluate the possibility of $\mathrm{S}-\mathrm{O}$ homolysis from $\mathrm{T}_{1}$ the transition state for the dissociation was located on the B3LYP surface and its energy was calculated at the MN12SX level. The barrier for bond scission from $T_{1}$ is thus predicted to be $14 \mathrm{kcal} / \mathrm{mol}$ and thus unlikely to provide a chemically relevant decay channel for the excited triplet state. Similar calculations on the trifluoromethanesulfonyl derivative, $\mathbf{1 b}$, provided similar results (see SI). 


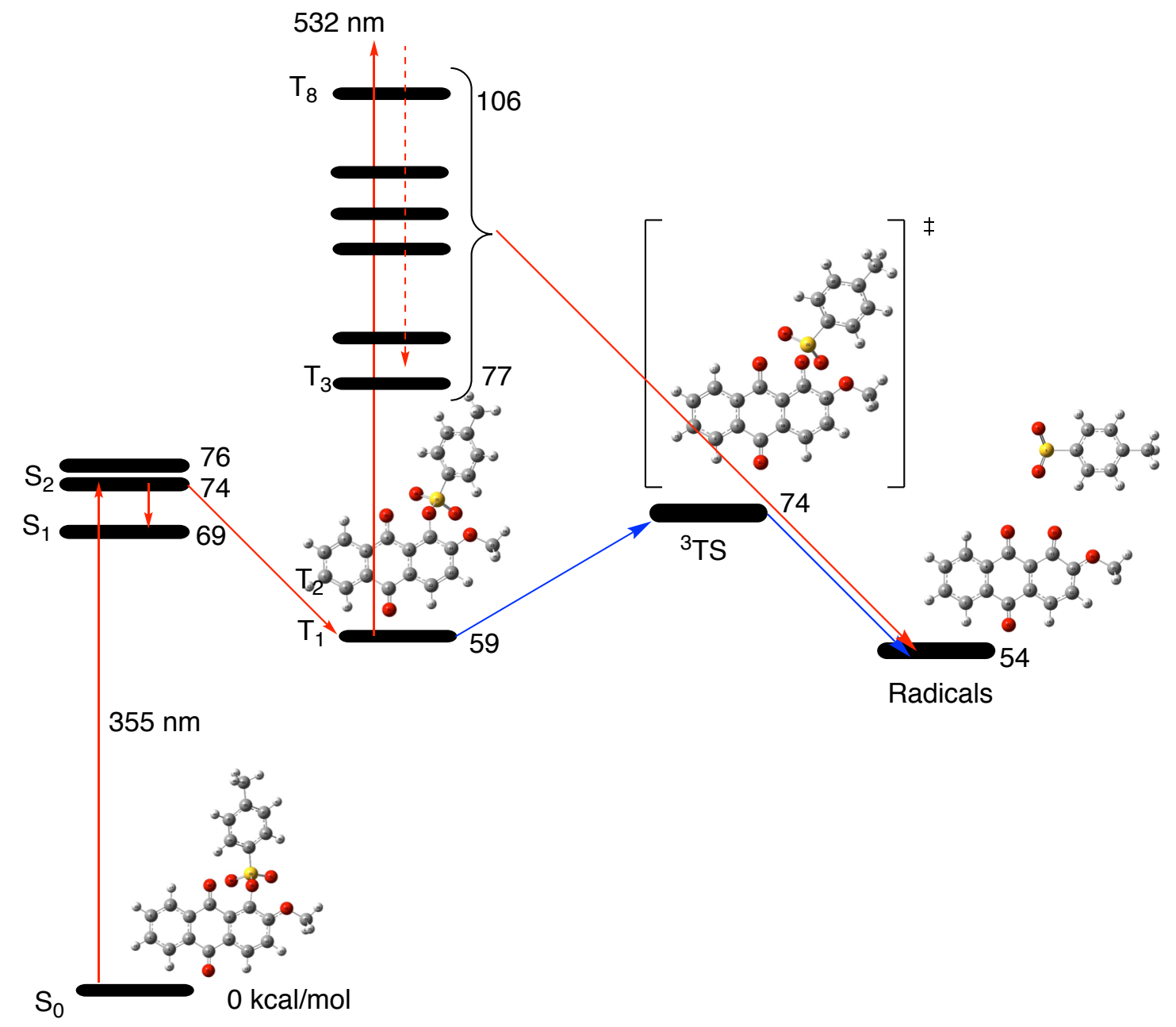

Figure 2. Energy level diagram for 1-photon and sequential 2-photon photolysis 1a. Energies of $S_{0}, T_{1}$, the radical pair, and transition state (TS) are derived from DFT calculations. Higher excited states in the singlet and triplet manifold are vertical energies derived from TD-DFT calculations.

s-TPA Experiments. The two arylsulfonate esters $\mathbf{1 a}$ and $\mathbf{1 b}$ examined in this study were prepared by sequential methylation and sulfonylation of the commercially available anthraquinone dye, alizarin (1,2-dihydroxyanthraquinone). Synthetic details and characterization data are available in the SI. The experiments described below show that anthraquinone sulfonate esters $\mathbf{1 a}$ and $\mathbf{1} \mathbf{b}$ are capable of generating $p$-toluenesulfonic acid ( $p$-TsOH) and triflic acid ( $\mathrm{TfOH})$, respectively (Scheme 4). 
Scheme 4. Photolysis of $\mathbf{1 a}$ and $\mathbf{1 b}$ to generate $p-\mathrm{TsOH}$ and $\mathrm{TfOH}$, respectively

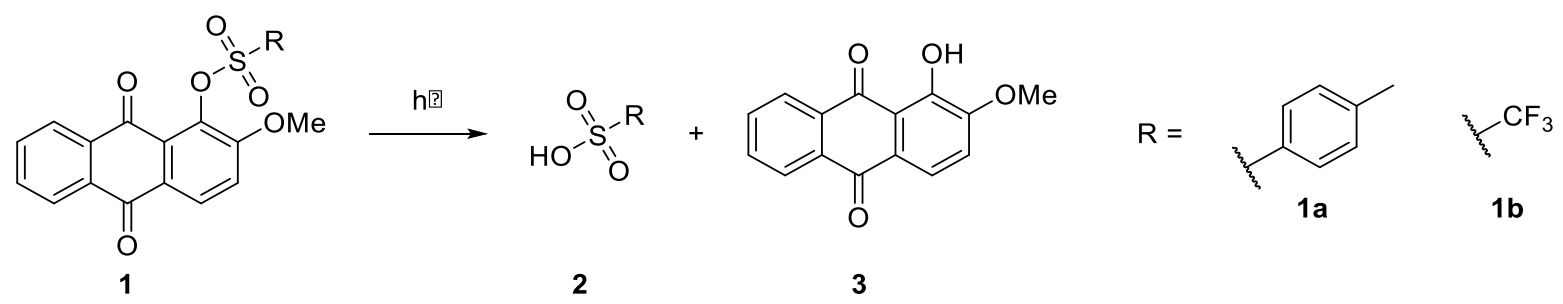

Photolysis of 1a in a $\mathrm{CD}_{3} \mathrm{CN}$ solution under high intensity conditions, using pulsed $(10 \mathrm{~Hz}, 15 \mathrm{~mJ}$, $7 \mathrm{~ns}) 355 \mathrm{~nm}$ light results in formation of $p$-TsOH. As illustrated in Figure 3, 6.67 minutes of photolysis converts approximately $79 \%$ of the substrate and provides reasonable yields (48\%) of the targeted acid. The yield of a s-TPA process should depend on both the total dose of light applied to the sample, as well as the intensity. In contrast, a conventional one-photon reaction would depend on the dose but be independent of the intensity. To test for this, low intensity photolysis of an identical solution of 1a using $355 \mathrm{~nm}$ at $5 \mathrm{~mJ} /$ pulse for 20 min (providing a consistent dose) was carried out for comparison purposes. In this case, the photolysis converts only $53 \%$ of the substrate and provides only $15 \%$ of the targeted acid.

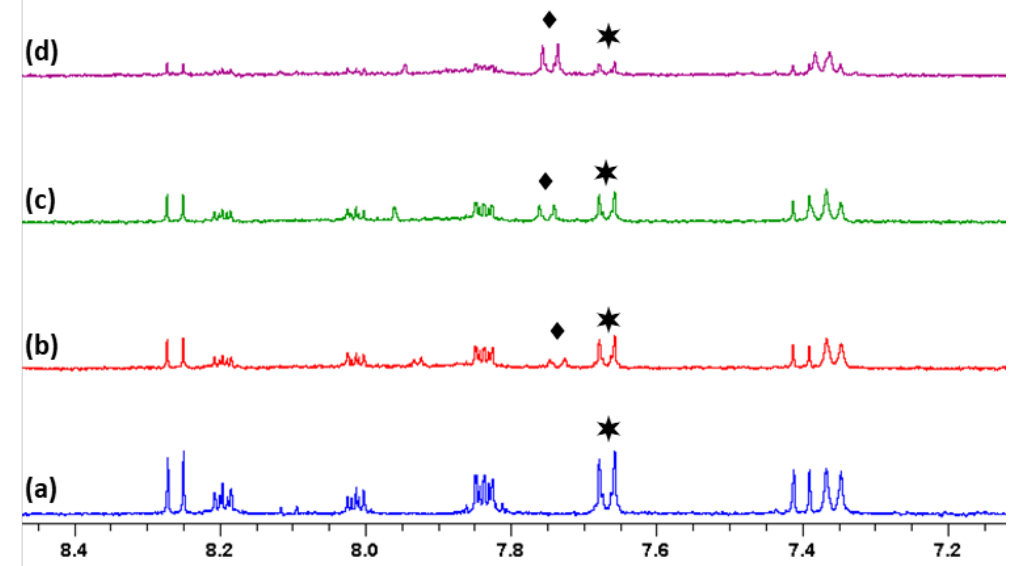

Figure 3. Monitoring formation of $p$ - $\mathrm{TsOH}(*)$ during the $355 \mathrm{~nm}$ pulsed photolysis of $1 \mathrm{a}(*)$ with constant dose of irradiation but varied power. (a) 1a, no photolysis; (b) 20 mins of irradiation at 5 $\mathrm{mJ} /$ pulse; (c) $10 \mathrm{mins}$ of irradiation at $10 \mathrm{~mJ} /$ pulse; (d) 6.67 mins of irradiation at $15 \mathrm{~mJ} / \mathrm{pulse}$

A similar intensity effect on photolysis rates can be observed by controlling the area of irradiation. A comparison was made between cases in which the total dose was kept constant, but the light intensity was varied by exposing identical samples to either a focused $\left(2.08 \times 10^{9} \mathrm{~mW} \mathrm{~cm}^{-2}\right)$ or an unfocused 
$\left(1.14 \times 10^{9} \mathrm{~mW} \mathrm{~cm}^{-2}\right)$ laser beam. As displayed in Table 1, light intensity at constant dose has a dramatic effect on both the conversion as well as the production of $p$-TsOH.

Table 1: Pulsed $355 \mathrm{~nm}$ photolysis of $\mathbf{1 a}$ in $\mathrm{CD}_{3} \mathrm{CN}$ with and without defocusing the laser beam

\begin{tabular}{|c|c|c|c|c|}
\hline Laser Beam & $\begin{array}{l}\text { Time } \\
(\min )\end{array}$ & $\begin{array}{l}355 \text { Power } \\
\text { (mJ/pulse) }\end{array}$ & $\%$ Conversion & $\begin{array}{l}\% \text { Yield } \\
p \text {-TsOH }\end{array}$ \\
\hline Focused & 10 & $7-9$ & 67 & 26 \\
\hline Unfocused & 10 & $7-9$ & 39 & 12 \\
\hline
\end{tabular}

Additional evidence for s-TPA come from two-color irradiation experiments. Calculations described in Figure 2 predict that several higher triplet states $\left(T_{3}-T_{8}\right)$ should be both accessible to visible light photolysis of $\mathrm{T}_{1}$ and also possess sufficient energy to allow for exothermic $\mathrm{S}-\mathrm{O}$ homolysis. Therefore, solutions of 1a were photolyzed with the pulsed laser at $355 \mathrm{~nm}, 532 \mathrm{~nm}$, and with both wavelengths simultaneously. The results are compared in Table 2. The addition of $532 \mathrm{~nm}$ irradiation dramatically enhances the rate of conversion of $1 \mathrm{a}$ and the production of $p$ - $\mathrm{TsOH}$. It should be noted that 1a does not absorb light at this wavelength, and indeed irradiation at $532 \mathrm{~nm}$ alone has a negligible effect on the sample. The efficiencies of acid production were assessed at low conversions by comparing the yield of acid as a function of photolysis times using a malachite green carbinol base assay (see SI). The results are shown in Figure 4. The addition of $532 \mathrm{~nm}$ pulses increases the rate of conversion by a factor of 4 relative to $355 \mathrm{~nm}$ alone.

Table 2. Yields of $p$-TsOH from pulsed photolysis of $1 \mathrm{a}$ in $\mathrm{CD}_{3} \mathrm{CN}$ with varying wavelengths of irradiation

\begin{tabular}{|c|c|c|c|c|c|}
\hline Entry & $\begin{array}{l}\text { Time } \\
(\min )\end{array}$ & $\begin{array}{l}355 \text { Power } \\
\text { (mJ/pulse) }\end{array}$ & $\begin{array}{l}532 \text { Power } \\
\text { (mJ/pulse) }\end{array}$ & $\%$ Conversion $^{\mathrm{a}}$ & $\begin{array}{c}\text { \% Yield } \\
p \text {-TsOH }\end{array}$ \\
\hline 1 & 10 & $8-10$ & $87-89$ & $94 \pm 3$ & $77 \pm 10$ \\
\hline 2 & 10 & $9-11$ & 0 & $58 \pm 7$ & $34 \pm 10$ \\
\hline 3 & 10 & 0 & $87-90$ & 0 & 0 \\
\hline 4 & 10 & 0 & 0 & 0 & 0 \\
\hline
\end{tabular}

${ }^{\mathrm{a}}$ Error bars are the result of triplicate experiments 


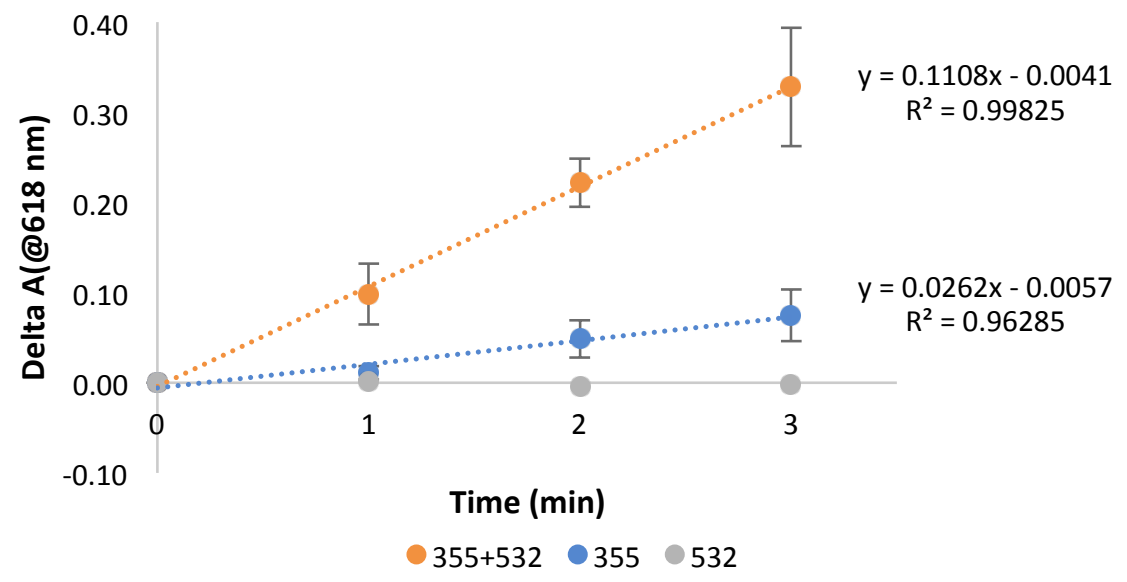

Figure 4. Monitoring formation of $p-\mathrm{TsOH}$ from the pulsed photolysis of $1 \mathrm{a}$ in acetonitrile using malachite green carbinol base as a $\mathrm{pH}$ indicator. Orange line: $355 \mathrm{~nm}+532 \mathrm{~nm}$ photolysis. Blue line: 355 $\mathrm{nm}$ photolysis. Grey line: $532 \mathrm{~nm}$ photolysis . Error bars are the result of triplicate experiments.

Photoacid generation through s-TPA can also be realized through CW irradiation using readily available diode lasers. In these experiments, solutions of 1a were photolyzed using a CW $447 \mathrm{~nm}$ diode laser (1a has a tail absorption at this wavelength) and acid production was quantified using a malachite green carbinol base assay (see SI for details). The dependence of acid production on laser intensity was measured at constant irradiation time. At modest laser powers, a one-photon process would show a linear dependence, whereas a two-photon process should depend on the square of the intensity. As illustrated in Figure 5, there is a quadratic dependence that fits to an order of 2.07. As implied in Figure 5, we find that photolysis rates become very slow at low light intensities. However with prolonged photolysis of 1a using conventional $350 \mathrm{~nm}$ lamps, we do observe some low conversion leading to complex mixtures, of which $p$-TsOH is only a minor component. 


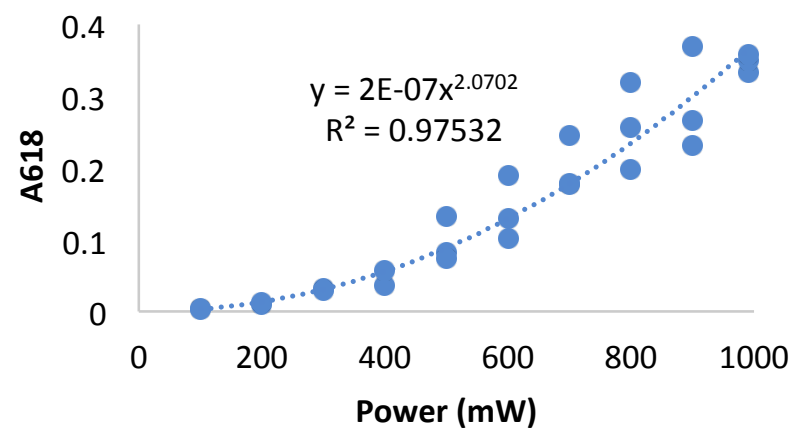

Figure 5. Acid yield from photolysis of 1a in acetonitrile with $447 \mathrm{~nm} \mathrm{CW}$ laser at a fixed irradiation time, but with varying power. Formation of $p-\mathrm{TsOH}$ monitored with malachite green carbinol base $\mathrm{pH}$ indicator

In order to generate a stronger acid, similar high intensity photolysis experiments were applied to the trifluoromethylsulfonyl derivative, $\mathbf{1 b}$, the results of which are summarized in Table 3 . In this case the yield of the corresponding sulfonic acid $(\mathrm{TfOH})$ was significantly lower. However, this result is consistent with the homolysis mechanism shown in Scheme 3. Excited state $\mathrm{S}-\mathrm{O}$ homolysis would provide the trifluoromethanesulfonyl radical which has previously been shown to rapidly eliminate $\mathrm{SO}_{2}$ forming the trifluoromethyl radical. ${ }^{69}$ In the presence of oxygen, the trifluoromethane radical will react to generate trifluoromethanol which, in turn, decomposes to form HF and fluorophosgene, the latter further hydrolyzing to form HF (Scheme 5).

Table 3. Yields of $\mathrm{TfOH}$ from pulsed photolysis of $\mathbf{1 b}$ in $\mathrm{CD}_{3} \mathrm{CN}$ with varying wavelengths of irradiation

\begin{tabular}{|c|c|c|c|c|c|}
\hline Entry & $\begin{array}{l}\text { Time } \\
\text { (min) }\end{array}$ & $\begin{array}{l}355 \text { Power } \\
\text { (mJ/pulse) }\end{array}$ & $\begin{array}{l}532 \text { Power } \\
\text { (mJ/pulse) }\end{array}$ & $\%$ Conversion $^{\mathrm{a}}$ & $\begin{array}{c}\% \text { Yield } \\
\text { Triflic Acid }^{\mathrm{a}}\end{array}$ \\
\hline 1 & 20 & $8-10$ & 88-91 & $81 \pm 1$ & $10 \pm 1$ \\
\hline 2 & 20 & $8-10$ & 0 & $48 \pm 0$ & $21 \pm 2$ \\
\hline 3 & 20 & 0 & $88-91$ & 8 & 0 \\
\hline 4 & 20 & 0 & 0 & 2 & 0 \\
\hline
\end{tabular}

${ }^{\mathrm{a}}$ Error bars are the result of triplicate experiments 
Scheme 5. Secondary pathways from decomposition of the trifluoromethanesulfonyl radical

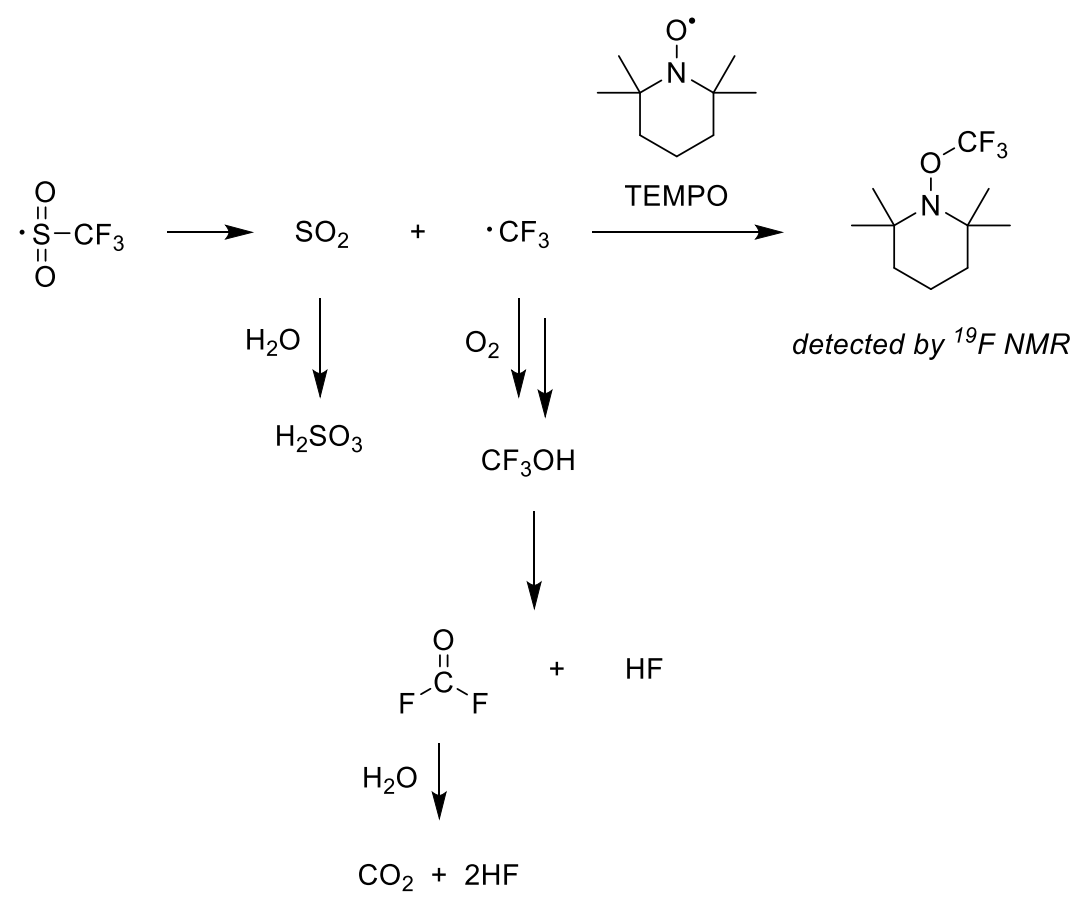

Support for the proposed secondary steps in Scheme 5 comes from a combination of total acid analysis, fluoride ion analysis, and TEMPO trapping experiments. The total acid produced under various high intensity photolysis conditions was quantified via acid-base titration and the results are reported in Table 4. Despite the low yields of $\mathrm{TfOH}$, two color photolysis of provides more than three equivalents of $\mathrm{H}^{+}$. If all of the secondary reactions depicted Scheme 5 occurred with unit efficiency, there would be four equivalents of acid produced ( 1 eq. of $\mathrm{H}_{2} \mathrm{SO}_{3}$ and 3 eq of $\mathrm{HF}$ ). However, the various radical intermediates produced in these reactions can undergo competing reactions, such as hydrogen atom abstraction from the solvent, and this will reduce the yield somewhat.

Table 4. Overall yields of acid resulting from the pulsed photolysis of $1 \mathbf{b}$ in $\mathrm{CH}_{3} \mathrm{CN}$

\begin{tabular}{|c|c|c|c|c|}
\hline Entry & $\begin{array}{l}\text { Time } \\
\text { (min) }\end{array}$ & $\begin{array}{l}355 \text { Power } \\
\text { (mJ/pulse) }\end{array}$ & $\begin{array}{l}532 \text { Power } \\
\text { (mJ/pulse) }\end{array}$ & $\%$ Yield Acid ${ }^{a}$ \\
\hline 1 & 20 & $9-10$ & $89-91$ & $332 \pm 13$ \\
\hline 2 & 20 & $9-10$ & 0 & $208 \pm 20$ \\
\hline 3 & 20 & 0 & $89-91$ & 0 \\
\hline 4 & 20 & 0 & 0 & 0 \\
\hline
\end{tabular}

${ }^{a}$ Error bars are the result of triplicate experiments 
Formation of $\mathrm{F}^{-}$, as predicted in Scheme 5 was also verified. Specifically, high intensity photolysis of $\mathbf{1 b}$ in $\mathrm{CH}_{3} \mathrm{CN}$ was carried out under the conditions described in Table 5. The resulting mixtures were then assayed for $\mathrm{F}^{-}$using a colorimetric procedure (see $\left.\mathrm{SI}\right)$. Two color $(355+532 \mathrm{~nm})$ photolysis provides the highest yields of both acid and $\mathrm{F}^{-}$and with $355 \mathrm{~nm}$ alone, the yields at are somewhat attenuated. This pattern is analogous to the behavior for $p$ - $\mathrm{TsOH}$ generation from 1a thus provide additional support for the s-TPA.

Table 5. Yield of $\mathrm{F}^{-}$resulting from the pulsed photolysis of $\mathbf{1 b}$ in $\mathrm{CH}_{3} \mathrm{CN}$

\begin{tabular}{|c|c|c|c|c|}
\hline Entry & $\begin{array}{l}\text { Time } \\
(\mathrm{min})\end{array}$ & $\begin{array}{l}355 \text { Power } \\
\text { (mJ/pulse) }\end{array}$ & $\begin{array}{l}532 \text { Power } \\
\text { (mJ/pulse) }\end{array}$ & $\%$ Yield $F^{-a}$ \\
\hline 1 & 20 & $8-10$ & $86-88$ & $171 \pm 16$ \\
\hline 2 & 20 & $8-10$ & 0 & $66 \pm 6$ \\
\hline 3 & 20 & 0 & $86-88$ & 25 \\
\hline 4 & 20 & 0 & 0 & 23 \\
\hline
\end{tabular}

${ }^{\mathrm{a}}$ Error bars are the result of triplicate experiments

The pathways in Scheme 5 were further supported by radical trapping experiments. In this case TEMPO as added to solutions of $\mathbf{1} \mathbf{b}$ which were subjected to high-intensity photolysis with $355 \mathrm{~nm}$ light and the $\mathrm{CF}_{3}$ adduct of TEMPO was detected via its characteristic ${ }^{19} \mathrm{~F}$ NMR resonance. ${ }^{70}$

The tosyl radical from s-TPA photolysis of 1 a does not show the same propensity for $\mathrm{SO}_{2}$ dissociation as does the $\mathrm{CF}_{3} \mathrm{SO}_{2} \bullet$ radical from $\mathbf{1 b}$. However, the effect of $\mathrm{O}_{2}$ on the product yields supports a similar homolysis mechanism. Specifically purging the photolysis samples with $\mathrm{N}_{2}$ results in similar photoconversion rates as air-equilibrated or $\mathrm{O}_{2}$ purged solutions but suppresses the yield of $p$ $\mathrm{TsOH}$ (Scheme 6, Table 6). The photoproduct mixtures from the anaerobic photolyses are complex and were not analyzed in detail, but it is reasonable to assume that they result from various non-specific reactions of the primary radicals.

Scheme 6. Photoacid generation from $\mathrm{O}_{2}$ trapping of the sulfonyl radical 5

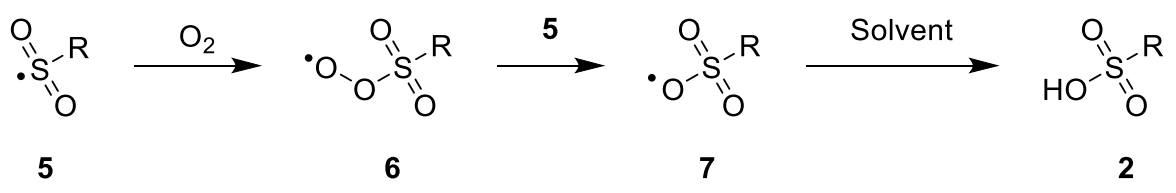


Table 6. Pulsed photolysis of $1 \mathrm{a}$ in $\mathrm{CD}_{3} \mathrm{CN}$ with varying atmospheres

\begin{tabular}{|c|c|c|c|c|c|}
\hline Atmosphere & $\begin{array}{l}\text { Time } \\
(\min )\end{array}$ & $\begin{array}{l}355 \text { Power } \\
\text { (mJ/pulse) }\end{array}$ & $\begin{array}{l}532 \text { Power } \\
\text { (mJ/pulse) }\end{array}$ & $\%$ Conversion & $\begin{array}{l}\text { \% Yield } \\
p \text {-TsOH }\end{array}$ \\
\hline Air & 10 & $8-10$ & $88-90$ & 89 & 64 \\
\hline $\mathrm{N}_{2}$ & 10 & $8-10$ & $88-90$ & 72 & 11 \\
\hline $\mathrm{O}_{2}$ & 10 & $8-10$ & $88-90$ & 88 & 63 \\
\hline
\end{tabular}

Laser Flash Photolysis Experiments. The intermediate that absorbs the second photon is assigned the to the triplet state $\left(T_{1}\right)$ of the anthraquinone derivative on the basis of laser flash photolysis (LFP) experiments. Specifically, a $\mathrm{CH}_{3} \mathrm{CN}$ solution of 1a was subjected to pulsed laser ( $355 \mathrm{~nm}, 10 \mathrm{~ns}, 50$ $\mathrm{mJ}$ ) photolysis and the resulting spectrum is displayed in Figure 6.

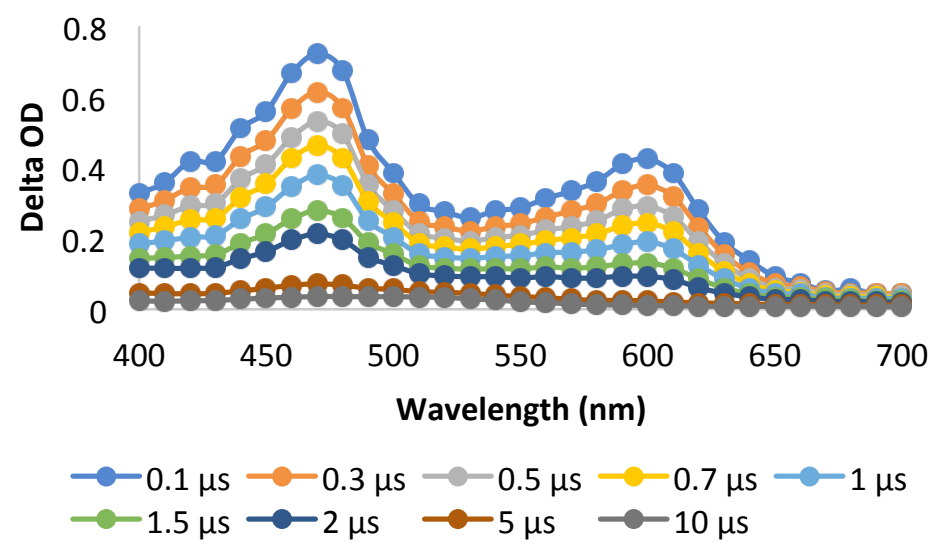

Figure 6. Transient absorption spectra from $355 \mathrm{~nm}$ pulsed photolysis of 1a in acetonitrile

Two transient absorption bands with maxima at $470 \mathrm{~nm}$ and $600 \mathrm{~nm}$ are formed immediately following the excitation pulse and decay in a first order fashion with a lifetime of $1.4 \mu$ s. These signals are assigned to the $T_{1}$ state of $1 \mathbf{a}$ on the basis of the following observations. (1) The shape and appearance of this spectrum matches spectra for triplet states of similar anthraquinone derivatives. ${ }^{71,72}$ (2) As is typical for excited triplet states, the lifetime of the detected species is significantly lower when the samples are purged with $\mathrm{O}_{2}$. (3) As displayed in Figure 7, TD-DFT calculations for the triplet-triplet absorption spectrum show reasonable agreement with the spectrum in Figure 6. LFP experiments on the trifluoromethanesulfonyl derivative, $\mathbf{1 b}$, provide similar results. 


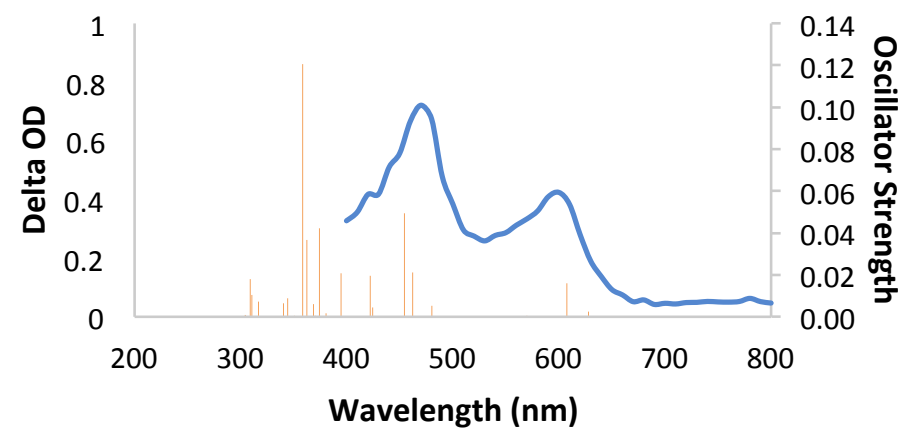

Figure 7. Orange bars: TD-DFT calculated triplet-triplet spectrum for 1a, Blue curve: experimental transient absorption spectrum from $355 \mathrm{~nm}$ pulsed photolysis of $1 \mathrm{a}$ at $0.1 \mu \mathrm{s}$

The absorption profile of $T_{1}$ is consistent with the s-TPA results. Although $532 \mathrm{~nm}$ is near a local minimum in the spectrum, there is still sufficient absorption at this wavelength to expect re-excitation. Likewise, $T_{1}$ also shows significant absorption at $447 \mathrm{~nm}$, consistent with the results shown in Figure 5. Given the substantial ground state absorption at $355 \mathrm{~nm}$, it was not possible to experimentally verify $T_{1}$ absorption at that wavelength. However, the TD-DFT calculations predict strong $\mathrm{T}_{1}$ absorptions (358 $\mathrm{nm}$, $f=0.1207)$ near this wavelength.

Scheme 7. Photolysis of 8 to generate $p$-TsOH

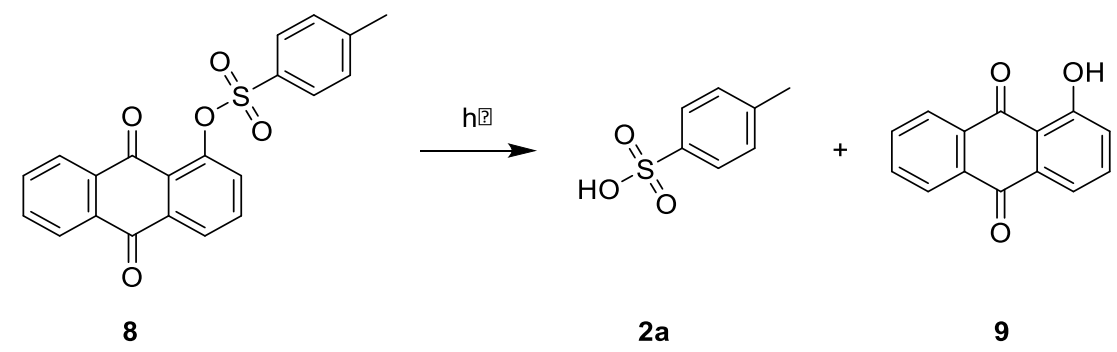

To provide further information on the role of the $T_{1}$ state in reexcitation, derivative 8 was prepared and tested (Scheme 7). A transient spectrum from pulsed photolysis of 8 ( $355 \mathrm{~nm}, 10 \mathrm{~ns}, 50$ $\mathrm{mJ}$ ) is shown in Figure 8. There is a maximum at $380 \mathrm{~nm}$ and a very weak tail from $400-700 \mathrm{~nm}$. This signal is attributed to the $T_{1}$ state of 8 as it is quenched by $\mathrm{O}_{2}$ and has a lifetime similar to that of $1 \mathrm{a}$ and 1b. 


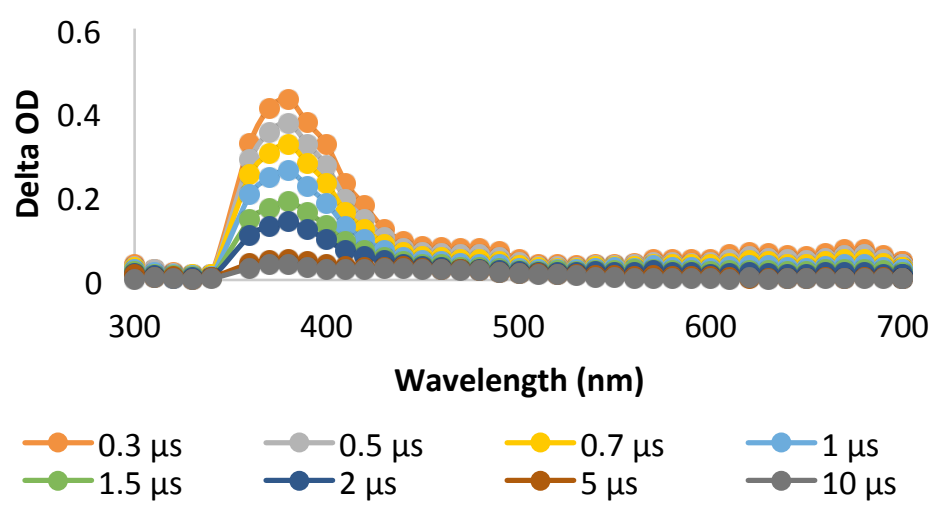

Figure 8. Transient absorption spectrum from $355 \mathrm{~nm}$ pulsed photolysis of $\mathbf{8}$ in acetonitrile

Compound $\mathbf{8}$ was photolyzed under the same two-color conditions as $\mathbf{1 a}$ and the results are shown in Table 7. Not surprisingly, irradiation with combined $355+532 \mathrm{~nm}$ light did not provide a significant enhancement when compared to irradiation with $355 \mathrm{~nm}$ light alone. These results are consistent with the second excitation occurring from $T_{1}$ - when that state has a significant absorption at $532 \mathrm{~nm}$, a two-color effect is observed. When $\mathrm{T}_{1}$ absorption at that wavelength is weak or absent, there is no enhancement.

While the non-linear and two-color experiments described above are consistent with the second absorption by $T_{1}$ there is a possibility that dissociation could be triggered through $S_{1}$, the first excited singlet state. Singlet anthraquinones tend to have very short lifetimes, ${ }^{72}$ but specific lifetimes for 1a and 1b are not available. It should be noted that the absorption spectra for the $S_{1}$ states of $\mathbf{1 a}$ and $\mathbf{8}$ have yet to be characterized. So there is a remote possibility that $1 a S_{1}$ absorbs at $532 \mathrm{~nm}$ and the corresponding excited state for $\mathbf{8}$ does not. In that case re-excitation of $S_{1}$ would still be a possible mechanism, However, given the known absorption spectra of the $T_{1}$ states and the expected short lifetimes for $S_{1}$ this would seem to be extremely unlikely.

Table 7. Pulsed photolysis of 8 in $\mathrm{CD}_{3} \mathrm{CN}$ with varying wavelengths of irradiation

\begin{tabular}{cccccc}
\hline Entry & $\begin{array}{c}\text { Time } \\
(\mathbf{m i n})\end{array}$ & $\begin{array}{c}\text { 355 Power } \\
\text { (mJ/pulse) }\end{array}$ & $\begin{array}{c}\text { 532 Power } \\
\text { (mJ/pulse) }\end{array}$ & $\begin{array}{c}\text { \% Conversion }^{\text {a }} \\
\text { (m) }\end{array}$ & $\begin{array}{c}\text { \% Yield } \\
\boldsymbol{p}_{\text {-TsOH }}{ }^{\text {a }}\end{array}$ \\
\hline 1 & 10 & $8-9$ & $87-88$ & $43 \pm 3$ & $15 \pm 1$ \\
2 & 10 & $8-9$ & 0 & $36 \pm 6$ & $17 \pm 2$ \\
3 & 10 & 0 & $87-88$ & 8 & 0 \\
4 & 10 & 0 & 0 & 0 & 0 \\
\hline
\end{tabular}


${ }^{\mathrm{a}}$ Error bars are the result of triplicate experiments

Cationic Photopolymerization. In order to determine the utility of $\mathbf{1 a}$ and $\mathbf{1 b}$ as s-TPA photoinitiators, these compounds were applied to the cationic polymerization of ethyl vinyl ether (EVE, Scheme 8). Specifically, $0.04 \mathrm{~mol} \%$ of $\mathbf{1 a}$ or $\mathbf{1 b}$ were combined with the monomer, EVE, and a small amount of $\mathrm{CH}_{2} \mathrm{Cl}_{2}$ was added to aid solubility. These mixtures were then subjected to high intensity twocolor photolysis as indicated in Figure $\mathbf{9}$. The results showed that both $\mathbf{1 a}$ and $\mathbf{1 b}$ were able to initiate polymerization and reach $100 \%$ monomer conversion and formation of poly(ethyl vinyl ether) was observed as shown in Figure 9. The signals corresponding to the vinylic protons of EVE are absent in the product mixture and new, broad signals at $1.2 \mathrm{ppm}$ and $3.5 \mathrm{ppm}$ are indicative of poly(ethyl vinyl ether). Control experiments where photolysis was applied but photoinitiator was omitted or where photoinitiator was added but no light was used showed insignificant conversion of monomer.

Scheme 8. Photopolymerization of EVE with $\mathbf{1 a}$ or $\mathbf{1 b}$
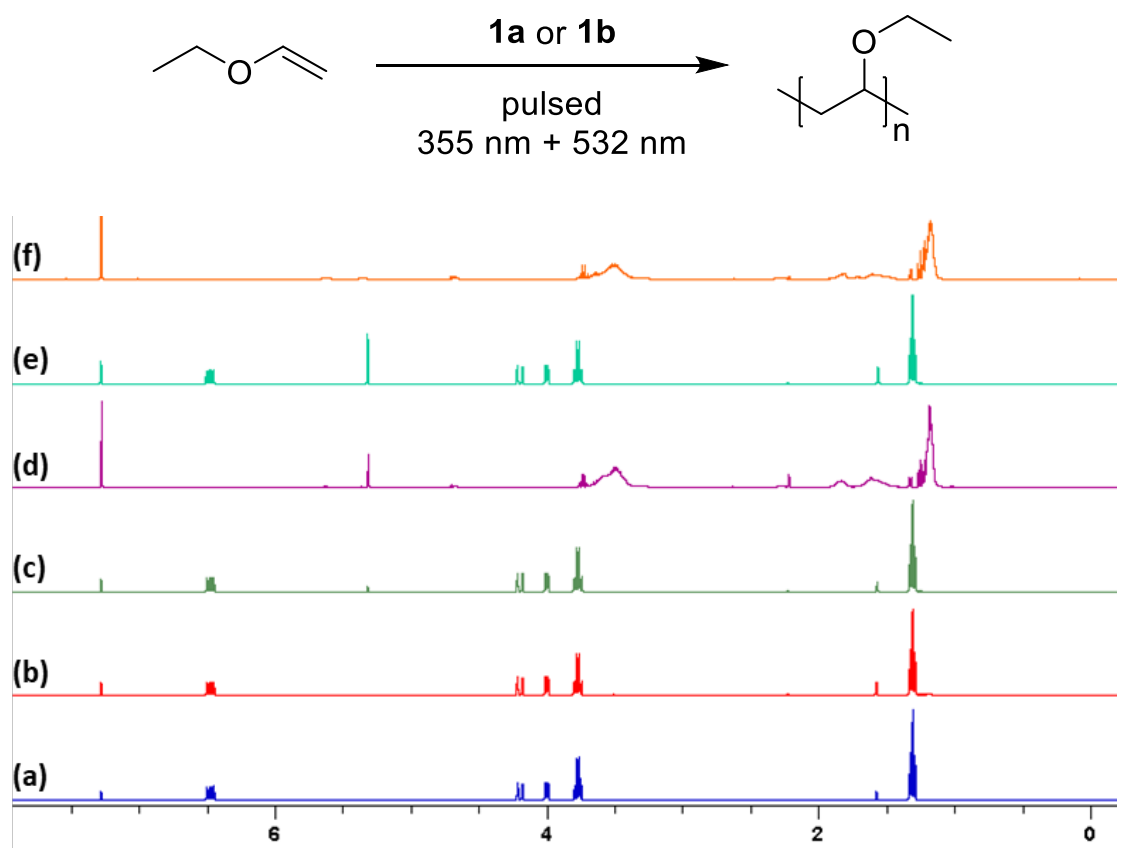

Figure 9. Photopolymerization of EVE with PAGs 1a and 1b. (a) EVE only, no photolysis; (b) EVE only, 10 mins of irradiation; (c) EVE+1b, 24 hour dark control; (d) EVE+1b, 10 mins of irradiation; (e) EVE+1a, 24 hour dark control; (f) EVE+1a, 2 hrs of irradiation

Conclusion. The calculations and experiments described in this paper demonstrate a strategy for the design of s-TPA photoacid generators. Anthraquinone derivatives $\mathbf{1 a}$ and $\mathbf{1 b}$ form their $\mathrm{T}_{1}$ state upon 
single photon excitation. Under high intensity photolysis conditions, a fraction of the $T_{1}$ states are reexcited causing $\mathrm{S}-\mathrm{O}$ homolysis. Subsequent reactions of the sulfonyl radical generate strong acids in excellent chemical yields. The resulting acids can be used to initiate cationic polymerization of vinyl ethers. Further developments of this approach will be to identify precursors that are activated using higher wavelength excitation and to reduce non-specific 1-photon photochemical reactions.

\section{References}

1. Yagci, Y.; Jockusch, S.; Turro, N. J., Photoinitiated Polymerization: Advances, Challenges, and Opportunities. Macromolecules 2010, 43 (15), 6245-6260.

2. Xu, J. T.; Shanmugam, S.; Duong, H. T.; Boyer, C., Organo-photocatalysts for photoinduced electron transfer-reversible addition-fragmentation chain transfer (PET-RAFT) polymerization. Polymer Chemistry 2015, 6 (31), 5615-5624.

3. McKenzie, T. G.; Fu, Q.; Wong, E. H. H.; Dunstan, D. E.; Qiao, G. G., Visible Light Mediated Controlled Radical Polymerization in the Absence of Exogenous Radical Sources or Catalysts. Macromolecules 2015, 48 (12), 3864-3872.

4. Chen, M.; Zhong, M. J.; Johnson, J. A., Light-Controlled Radical Polymerization: Mechanisms, Methods, and Applications. Chemical Reviews 2016, 116 (17), 10167-10211.

5. Pan, X. C.; Tasdelen, M. A.; Laun, J.; Junkers, T.; Yagci, Y.; Matyjaszewski, K., Photomediated controlled radical polymerization. Progress in Polymer Science 2016, 62, 73-125.

6. Buss, B. L.; Miyake, G. M., Photoinduced Controlled Radical Polymerizations Performed in Flow: Methods, Products, and Opportunities. Chemistry of Materials 2018, 30 (12), 3931-3942.

7. Lewis, R. W.; Evans, R. A.; Malic, N.; Saito, K.; Cameron, N. R., Ultra-fast aqueous polymerisation of acrylamides by high power visible light direct photoactivation RAFT polymerisation. Polymer Chemistry 2018, 9 (1), 60-68.

8. Corrigan, N.; Yeow, J.; Judzewitsch, P.; Xu, J. T.; Boyer, C., Seeing the Light: Advancing Materials Chemistry through Photopolymerization. Angewandte Chemie-International Edition 2019, 58 (16), 51705189.

9. Garra, P.; Fouassier, J. P.; Lakhdar, S.; Yagci, Y.; Lalevee, J., Visible light photoinitiating systems by charge transfer complexes: Photochemistry without dyes. Progress in Polymer Science 2020, 107, 16. 10. Uchino, S. I.; Tanaka, T.; Ueno, T.; Iwayanagi, T.; Hayashi, N., AZIDE-NOVOLAK RESIN NEGATIVE PHOTORESIST FOR I-LINE PHASE-SHIFTING LITHOGRAPHY. Journal of Vacuum Science \& Technology $B$ 1991, 9 (6), 3162-3165.

11. Teo, D. W. Y.; Jamal, Z.; Phua, H. Y.; Tang, C. G.; Png, R. Q.; Chua, L. L., Nearly $100 \%$ Photocrosslinking Efficiency in Ultrahigh Work Function Hole-Doped Conjugated Polymers Using Bis(fluorophenyl azide) Additives. Acs Applied Materials \& Interfaces 2019, 11 (51), 48103-48112.

12. Leyva, E.; Platz, M. S.; Loredo-Carrillo, S. E.; Aguilar, J., Fluoro Aryl Azides: Synthesis, Reactions and Applications. Current Organic Chemistry 2020, 24 (11), 1161-1180.

13. Schock, M.; Brase, S., Reactive \& Efficient: Organic Azides as Cross-Linkers in Material Sciences. Molecules 2020, 25 (4), 29. 
14. Teo, D. W. Y.; Jamal, Z.; Seah, Q. J.; Png, R. Q.; Chua, L. L., General bis(fluorophenyl azide) photocrosslinkers for conjugated and non-conjugated polyelectrolytes. Journal of Materials Chemistry C 2020, $8(1), 253-261$.

15. Crivello, J. V., The discovery and development of onium salt cationic photoinitiators. Journal of Polymer Science Part a-Polymer Chemistry 1999, 37 (23), 4241-4254.

16. Michaudel, Q.; Kottisch, V.; Fors, B. P., Cationic Polymerization: From Photoinitiation to Photocontrol. Angewandte Chemie-International Edition 2017, 56 (33), 9670-9679.

17. Michaudel, Q.; Chauvire, T.; Kottisch, V.; Supej, M. J.; Stawiasz, K. J.; Shen, L. X.; Zipfel, W. R.; Abruna, H. D.; Freed, J. H.; Fors, B. P., Mechanistic Insight into the Photocontrolled Cationic Polymerization of Vinyl Ethers. Journal of the American Chemical Society 2017, 139 (43), 15530-15538. 18. Dumur, F., Recent Advances on Visible Light Metal-Based Photocatalysts for Polymerization under Low Light Intensity. Catalysts 2019, 9 (9), 40.

19. Bouzrati-Zerelli, M.; Frigoli, M.; Dumur, F.; Graff, B.; Fouassier, J. P.; Lalevee, J., Design of novel photobase generators upon violet LEDs and use in photopolymerization reactions. Polymer 2017, 124, 151-156.

20. Zivic, N.; Kuroishi, P. K.; Dumur, F.; Gigmes, D.; Dove, A. P.; Sardon, H., Recent Advances and Challenges in the Design of Organic Photoacid and Photobase Generators for Polymerizations. Angewandte Chemie-International Edition 2019, 58 (31), 10410-10422.

21. Crivello, J. V., Design of Photoacid Generating Systems. Journal of Photopolymer Science and Technology 2009, 22 (5), 575-582.

22. Martin, C. J.; Rapenne, G.; Nakashima, T.; Kawai, T., Recent progress in development of photoacid generators. Journal of Photochemistry and Photobiology C: Photochemistry Reviews 2018, 34, 41-51.

23. Kuznetsova, N. A.; Malkov, G. V.; Gribov, B. G., Photoacid generators. Application and current state of development. Russian Chemical Reviews 2020, 89 (2), 173-190.

24. Belfield, K. D.; Yao, S.; Bondar, M. V., Two-photon Absorbing Photonic Materials: From Fundamentals to Applications. In Photoresponsive Polymers I, Springer-Verlag Berlin: Berlin, 2008; Vol. 213, pp 97-156.

25. Maruo, S.; Fourkas, J. T., Recent progress in multiphoton microfabrication. Laser \& Photonics Reviews 2008, 2 (1-2), 100-111.

26. Pawlicki, M.; Collins, H. A.; Denning, R. G.; Anderson, H. L., Two-Photon Absorption and the Design of Two-Photon Dyes. Angewandte Chemie-International Edition 2009, 48 (18), 3244-3266.

27. Fourkas, J. T.; Petersen, J. S., 2-Colour photolithography. Physical Chemistry Chemical Physics 2014, 16 (19), 8731-8750.

28. Fourkas, J. T., FUNDAMENTALS OF TWO-PHOTON FABRICATION. In Three-Dimensional Microfabrication Using Two-Photon Polymerization: Fundamentals, Technology, and Applications, Baldacchini, T., Ed. William Andrew Inc: Norwich, 2016; pp 45-61.

29. Houk, A. L.; Givens, R. S.; Elles, C. G., Two-Photon Activation of p-Hydroxyphenacyl Phototriggers: Toward Spatially Controlled Release of Diethyl Phosphate and ATP. Journal of Physical Chemistry B 2016, 120 (12), 3178-3186.

30. Alabugin, A., Near-IR Photochemistry for Biology: Exploiting the Optical Window of Tissue. Photochemistry and Photobiology 2019, 95 (3), 722-732.

31. Fang, H. X.; Zhang, H.; Li, L.; Ni, Y.; Shi, R. R.; Li, Z.; Yang, X. K.; Ma, B.; Zhang, C. W.; Wu, Q.; Yu, C. M.; Yang, N. D.; Yao, S. Q.; Huang, W., Rational Design of a Two-Photon Fluorogenic Probe for Visualizing Monoamine Oxidase A Activity in Human Glioma Tissues. Angewandte Chemie-International Edition 2020, 59 (19), 7536-7541.

32. Bhattacharjee, N.; Urrios, A.; Kanga, S.; Folch, A., The upcoming 3D-printing revolution in microfluidics. Lab on a Chip 2016, 16 (10), 1720-1742. 
33. Schwarzle, D.; Hou, X. Q.; Prucker, O.; Ruhe, J., Polymer Microstructures through Two-Photon Crosslinking. Advanced Materials 2017, 29 (39), 6.

34. Del Bonis-O'Donnell, J. T.; Page, R. H.; Beyene, A. G.; Tindall, E. G.; McFarlane, I. R.; Landry, M. P., Dual Near-Infrared Two-Photon Microscopy for Deep-Tissue Dopamine Nanosensor Imaging. Advanced Functional Materials 2017, 27 (39), 10.

35. Hennig, A. L. K.; Deodato, D.; Asad, N.; Herbivo, C.; Dore, T. M., Two-Photon Excitable Photoremovable Protecting Groups Based on the Quinoline Scaffold for Use in Biology. Journal of Organic Chemistry 2020, 85 (2), 726-744.

36. Bohineust, A.; Garcia, Z.; Corre, B.; Lemaitre, F.; Bousso, P., Optogenetic manipulation of calcium signals in single T cells in vivo. Nature Communications 2020, 11 (1), 10.

37. McGimpsey, W. G.; Scaiano, J. C., A 2-PHOTON STUDY OF THE RELUCTANT NORRISH TYPE-I REACTION OF BENZIL. Journal of the American Chemical Society 1987, 109 (7), 2179-2181.

38. Scaiano, J. C.; Johnston, L. J.; McGimpsey, W. G.; Weir, D., PHOTOCHEMISTRY OF ORGANICREACTION INTERMEDIATES - NOVEL REACTION PATHS INDUCED BY 2-PHOTON LASER EXCITATION. Accounts of Chemical Research 1988, 21 (1), 22-29.

39. Gannon, T.; McGimpsey, W. G., 2-LASER-SENSITIZED DECOMPOSITION OF CARBONTETRACHLORIDE - PHOTOACID GENERATION. Journal of Organic Chemistry 1993, 58 (21), 5639-5642. 40. Scaiano, J. C.; Arnold, B. R.; McGimpsey, W. G., 2-LASER, 2-COLOR PHOTOCHEMISTRY FROM UPPER TRIPLET-STATES OF 2-BROMONAPHTHALENE AND 9-BROMOPHENANTHRENE IN BENZENE. Journal of Physical Chemistry 1994, 98 (21), 5431-5434.

41. Miranda, M. A.; Perez-Prieto, J.; Font-Sanchis, E.; Scaiano, J. C., One- vs two-photon processes in the photochemistry of 1,n-dihaloalkanes. Accounts of Chemical Research 2001, 34 (9), 717-726.

42. Sakamoto, M.; Kim, S. S.; Fujitsuka, M.; Majima, T., Design of cyclic reaction driven by two-color two-photon excitation. Journal of Physical Chemistry C 2007, 111 (19), 6917-6919.

43. O'Connor, N. A.; Berro, A. J.; Lancaster, J. R.; Gu, X. Y.; Jockusch, S.; Nagai, T.; Ogata, T.; Lee, S.; Zimmerman, P.; Willson, C. G.; Turro, N. J., Toward the Design of a Sequential Two Photon Photoacid Generator for Double Exposure Photolithography. Chemistry of Materials 2008, 20 (24), 7374-7376.

44. Yamaji, M.; Nishio, M., Photochemical decomposition of amidobiphenyls in highly excited triplet states studied by stepwise two-color laser photolysis. Journal of Photochemistry and Photobiology aChemistry 2008, 193 (2-3), 288-293.

45. Yamaji, M., Stepwise two-color laser photolysis studies of alpha-cleavage in highly excited triplet states of alpha-acyl-4-phenylphenols. Photochemical \& Photobiological Sciences 2008, 7 (6), 711-717.

46. Yamaji, M.; Cai, X. C.; Sakamoto, M.; Fujitsuka, M.; Majima, T., Photodecomposition Profiles of beta-Bond Cleavage of Phenylphenacyl Derivatives in the Higher Triplet Excited States during Stepwise Two-Color Two-Laser Flash Photolysis. Journal of Physical Chemistry A 2008, 112 (45), 11306-11311. 47. Yamaji, M.; Cai, X.; Sakamoto, M.; Fujitsuka, M.; Majima, T., alpha-Bond Dissociation of pPhenylbenzoyl Derivatives in the Higher Triplet Excited State Studied by Two-Color Two-Laser Flash Photolysis. Journal of Physical Chemistry A 2009, 113 (9), 1696-1703.

48. Kobayashi, Y.; Mutoh, K.; Abe, J., Stepwise two-photon absorption processes utilizing photochromic reactions. Journal of Photochemistry and Photobiology C-Photochemistry Reviews 2018, 34, 2-28.

49. Marchini, M.; Gualandi, A.; Mengozzi, L.; Franchi, P.; Lucarini, M.; Cozzi, P. G.; Balzani, V.; Ceroni, P., Mechanistic insights into two-photon-driven photocatalysis in organic synthesis. Physical Chemistry Chemical Physics 2018, 20 (12), 8071-8076.

50. Thum, M. D.; Falvey, D. E., Photoreleasable Protecting Groups Triggered by Sequential TwoPhoton Absorption of Visible Light: Release of Carboxylic Acids from a Linked Anthraquinone-NAlkylpicolinium Ester Molecule. Journal of Physical Chemistry A 2018, 122 (12), 3204-3210. 
51. Uno, T.; Koga, M.; Sotome, H.; Miyasaka, H.; Tamai, N.; Kobayashi, Y., Stepwise Two-PhotonInduced Electron Transfer from Higher Excited States of Noncovalently Bound Porphyrin-CdS/ZnS Core/Shell Nanocrystals. Journal of Physical Chemistry Letters 2018, 9 (24), 7098-7104.

52. Kobayashi, Y.; Mutoh, K.; Abe, J., Stepwise two-photon absorption processes utilizing photochromic reactions. Journal of Photochemistry and Photobiology C: Photochemistry Reviews 2018, 34, 2-28.

53. Brandl, F.; Bergwinkl, S.; Allacher, C.; Dick, B., Consecutive Photoinduced Electron Transfer (conPET): The Mechanism of the Photocatalyst Rhodamine 6G. Chemistry-a European Journal 2020, 26 (35), 7946-7954.

54. Xia, Y.; Peng, L., Photoactivatable Lipid Probes for Studying Biomembranes by Photoaffinity Labeling. Chemical Reviews 2013, 113 (10), 7880-7929.

55. Yue, X.; Yanez, C. O.; Yao, S.; Belfield, K. D., Selective Cell Death by Photochemically Induced pH Imbalance in Cancer Cells. Journal of the American Chemical Society 2013, 135 (6), 2112-2115.

56. Fadhel, A. A.; Yue, X.; Ghazvini Zadeh, E. H.; Bondar, M. V.; Belfield, K. D., Pegylated and nanoparticle-conjugated sulfonium salt photo triggers necrotic cell death. (1178-2013 (Electronic)).

57. O'Connor, N. A.; Berro, A. J.; Lancaster, J. R.; Gu, X.; Jockusch, S.; Nagai, T.; Ogata, T.; Lee, S.; Zimmerman, P.; Willson, C. G.; Turro, N. J., Toward the Design of a Sequential Two Photon Photoacid Generator for Double Exposure Photolithography. Chemistry of Materials 2008, 20 (24), 7374-7376.

58. Demchenko, A. P.; Tomin, V. I.; Chou, P. T., Breaking the Kasha Rule for More Efficient Photochemistry. Chemical Reviews 2017, 117 (21), 13353-13381.

59. Kitchin, A. D.; Velate, S.; Chen, M.; Ghiggino, K. P.; Smith, T. A.; Steer, R. P., Photophysics of a dithioester RAFT polymerization agent and the acenaphthenyl model light-harvesting chromophore. Photochemical \& Photobiological Sciences 2007, 6 (8), 853-856.

60. Maciejewski, A.; Steer, R. P., THE PHOTOPHYSICS, PHYSICAL PHOTOCHEMISTRY, AND RELATED SPECTROSCOPY OF THIOCARBONYLS. Chemical Reviews 1993, 93 (1), 67-98.

61. Thum, M. D.; Wolf, S.; Falvey, D. E., State-Dependent Photochemical and Photophysical Behavior of Dithiolate Ester and Trithiocarbonate Reversible Addition-Fragmentation Chain Transfer Polymerization Agents. The Journal of Physical Chemistry A 2020, 124 (21), 4211-4222.

62. Cai, X. C.; Sakamoto, M.; Yamaji, M.; Fujitsuka, M.; Majima, T., C-O bond cleavage of benzophenone substituted by 4-CH2OR ( $\mathrm{R}=\mathrm{C} 6 \mathrm{H} 5$ and $\mathrm{CH} 3)$ with stepwise two-photon excitation. Journal of Physical Chemistry A 2005, 109 (27), 5989-5994.

63. Cai, X.; Sakamoto, M.; Yamaji, M.; Fujitsuka, M.; Majima, T., C-O-bond cleavage of esters with a naphthyl group in the higher triplet excited state during two-color two-laser flash photolysis. Chemistrya European Journal 2007, 13 (11), 3143-3149.

64. Andraos, J.; Barclay, G. G.; Medeiros, D. R.; Baldovi, M. V.; Scaiano, J. C.; Sinta, R., Model Studies on the Photochemistry of Phenolic Sulfonate Photoacid Generators. Chemistry of Materials 1998, 10 (6), 1694-1699.

65. Terpolilli, M.; Merli, D.; Protti, S.; Dichiarante, V.; Fagnoni, M.; Albini, A., Cationic and radical intermediates in the acid photorelease from aryl sulfonates and phosphates. Photochemical \& Photobiological Sciences 2011, 10 (1), 123-127.

66. Lamola, A. A.; Hammond, G. S., Mechanisms of Photochemical Reactions in Solution. XXXIII. Intersystem Crossing Efficiencies. The Journal of Chemical Physics 1965, 43 (6), 2129-2135.

67. Herkstroeter, W. G.; Lamola, A. A.; Hammond, G. S., Mechanisms of Photochemical Reactions in Solution. XXVIII.1 Values of Triplet Excitation energies of Selected Sensitizers. Journal of the American Chemical Society 1964, 86 (21), 4537-4540.

68. Guthrie, J. P.; Gallant, R. T., Thermodynamics of methanesulfonic acid revisited. Canadian Journal of Chemistry 2000, 78 (10), 1295-1298. 
69. Bertrand, F.; Le Guyader, F.; Liguori, L.; Ouvry, G.; Quiclet-Sire, B.; Seguin, S.; Zard, S. Z., $\alpha-$ Scission of sulfonyl radicals: a versatile process for organic synthesis. Comptes Rendus de l'Académie des Sciences - Series IIC - Chemistry 2001, 4 (7), 547-555.

70. Wang, X.; Ye, Y.; Zhang, S.; Feng, J.; Xu, Y.; Zhang, Y.; Wang, J., Copper-Catalyzed C(sp3)-C(sp3) Bond Formation Using a Hypervalent lodine Reagent: An Efficient Allylic Trifluoromethylation. Journal of the American Chemical Society 2011, 133 (41), 16410-16413.

71. Hamanoue, K.; Nakayama, T.; Kajiwara, Y.; Yamaguchi, T.; Teranishi, H., The lowest triplet states of anthraquinone and chloroanthraquinones: The 1-chloro, 2-chloro, 1,5-dichloro, and 1,8-dichloro compounds. The Journal of Chemical Physics 1987, 86 (12), 6654-6659.

72. van Ramesdonk, H. J.; Bakker, B. H.; Groeneveld, M. M.; Verhoeven, J. W.; Allen, B. D.; Rostron, J. P.; Harriman, A., Ultrafast Intersystem Crossing in 9,10-Anthraquinones and Intramolecular Charge Separation in an Anthraquinone-Based Dyad. The Journal of Physical Chemistry A 2006, 110 (49), 1314513150. 